\title{
Aqueous Processing Material Accountability Instrumentation
}

\author{
Robert Bean
}

September 2007

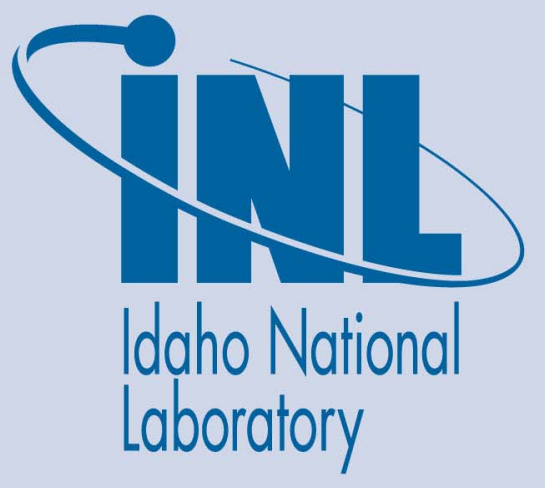

The INL is a U.S. Department of Energy National Laboratory operated by Battelle Energy Alliance 
INL/EXT-07-13431

\title{
Aqueous Processing Material Accountability Instrumentation
}

\author{
Robert Bean
}

September 2007

\begin{abstract}
Idaho National Laboratory
Nuclear Nonproliferation

Idaho Falls, Idaho 83415
\end{abstract}

Prepared for the

U.S. Department of Energy

Office of Nuclear Energy

Under DOE Idaho Operations Office

Contract DE-AC07-05ID14517 


\section{DISCLAIMER}

This information was prepared as an account of work sponsored by an agency of the U.S. Government. Neither the U.S. Government nor any agency thereof, nor any of their employees, makes any warranty, expressed or implied, or assumes any legal liability or responsibility for the accuracy, completeness, or usefulness, of any information, apparatus, product, or process disclosed, or represents that its use would not infringe privately owned rights. References herein to any specific commercial product, process, or service by trade name, trade mark, manufacturer, or otherwise, does not necessarily constitute or imply its endorsement, recommendation, or favoring by the U.S. Government or any agency thereof. The views and opinions of authors expressed herein do not necessarily state or reflect those of the U.S. Government or any agency thereof. 



\begin{abstract}
Increased use of nuclear power will require new facilities. The U.S. has not built a new spent nuclear fuel reprocessing facility for decades. Reprocessing facilities must maintain accountability of their nuclear fuel. This survey reports on the techniques used in current aqueous reprocessing facilities, and provides references to source materials to assist facility design efforts.
\end{abstract}




\section{CONTENTS}

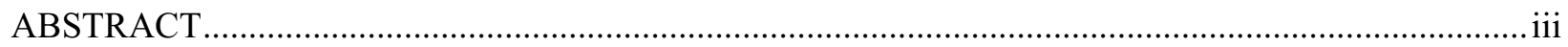

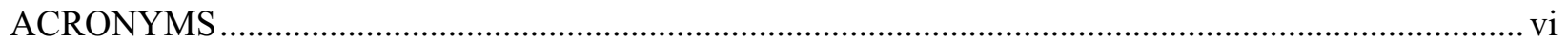

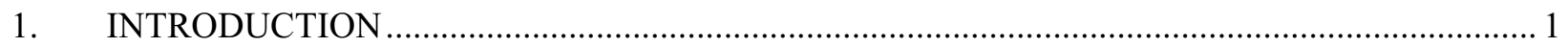

2. DESCRIPTION OF MATERIAL FLOW FOR REPROCESSING FACILITIES.......................... 1

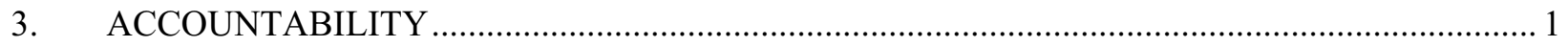

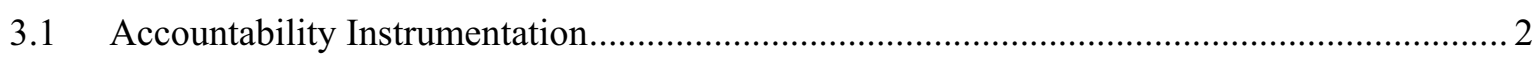

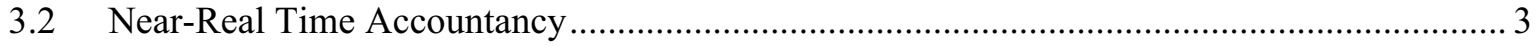

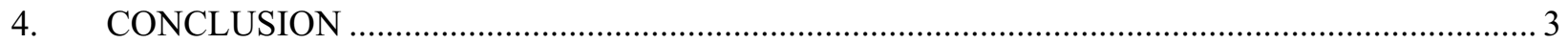

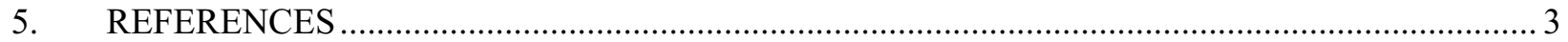




\section{ACRONYMS}

HKED Hydrib K-Edge Densitometry

HPG High Purity Germanium

IAEA International Atomic Energy Agency

ICP-MS Inductively Coupled Plasma Mass Spectroscopy

KED K-Edge Densitometry

NDA Nondestructive Assay

NRTA Near Real Time Accountancy

PUREX Plutonium and Uranium Extraction

RPP Rokkasho Reprocessing Plant

SNF Spent Nuclear Fuel

UREX Uranium Extraction

XRF X-Ray Fluorescence 


\section{Aqueous Processing Material Accountability Instrumentation}

\section{INTRODUCTION}

The worldwide expansion of nuclear power, especially within the U.S., will require new power reactors, enrichment plants, and waste disposal and reprocessing facilities. A new commercial reprocessing facility has not been built or operated within the U.S. for decades. ${ }^{1}$ Consequently, the knowledge base among U.S. scientists and engineers, with respect to what is needed to account for nuclear material within such a plant, is limited.

This survey reports on the techniques applied to operating aqueous reprocessing plants in other countries and references source materials from which knowledgecan be drawn by designers of the next generation of facilities.

\section{DESCRIPTION OF MATERIAL FLOW IN AQUEOUS REPROCESSING FACILITIES}

Assemblies of spent nuclear fuel (SNF) packaged in casks arrive at the reprocessing facility either by truck or railcar. These assemblies are typically unloaded into spent fuel storage pools until they can be processed. When processed, the assemblies are chopped into small (typically $2-5 \mathrm{~cm}$ long) pieces and dissolved into an acidic solution. The accountable nuclear material (fuel) dissolves into the acid solution and it remains in solution until the final product is formed. The solution is transferred to an accountability tank where samples are taken to establish the beginning inventory of nuclear material. Regardless of the exact plant process used (UREX, PUREX, pulsed columns, centrifugal contactors, etc.), the result is a series of product and waste streams. The product streams are oxide powder $\left(\mathrm{UO}_{2}, \mathrm{PuO}_{2}\right.$, mixed $\mathrm{U} / \mathrm{Pu}$ oxide, etc.) and the waste streams are liquid, solid (filters, cladding hulls, etc.), and exhaust gases. The product oxides are placed into containers that will be stored in onsite vaults, transferred to an onsite fuel fabrication facility, or shipped to another facility for use or final disposition.

\section{ACCOUNTABILITY}

The host country, and therefore the facility operator, will have a national program of safeguards. ${ }^{2}$ The nuclear material must be accounted for at each stage, with measurement programs and measurement control programs established as needed. ${ }^{3}$ The operator will take samples at various locations in the plant, beginning with the accountability tank. The typical measurement, then, is a volumetric measure of the particular tank coupled with the nuclear material concentration. During normal operation, accountability measurements will not be performed again until the oxide product step, although the movement of the nuclear material through the process will be monitored via simple radiation detectors. The oxide product will be weighed, and a sample will be taken to again determine the nuclear material concentration. Waste streams will be measured to determine the nuclear material quantity, or conversely, to determine that nuclear material quantities are below accountable levels, before transfer to a waste facility.

There will also be safeguards in place through the International Atomic Energy Agency (IAEA). ${ }^{4,5}$ The principal responsibility of the IAEA is to verify that the operations are as declared by the operator. ${ }^{6,7}$ The IAEA will perform independent measurements, with separate (but similar) instruments where possible. When separate instruments are not feasible, independent and authenticated data signals will be established. ${ }^{8}$ The IAEA also needs the instruments to be largely unattended. ${ }^{9}$ The overall process and key measurement points are described in the report of the ASA-100 group. ${ }^{10}$ To facilitate accountability efforts, the plant is divided into multiple material balance areas over which the nuclear material inventory 
is determined and verified. ${ }^{11}$ While the IAEA will make use of samples (especially at the accountability tank), the majority of their measurements will be nondestructive assay of product and waste streams, with process monitoring (tank level, flow meters, etc.) and containment/surveillance (seals, tamper indicating covers, cameras, etc.) to allow them to follow nuclear material movement and verify that it occurred as declared. ${ }^{12,13,14,15}$

\subsection{Accountability Instrumentation}

Various classes of instruments are used to measure accountability. Many are described in Sandia report SAND2005-6223, ${ }^{16}$ which also presents currently reported uncertainties. Los Alamos and other sites have published reports describing the state-of-the-art at the time that the Rokkasho Reprocessing Plant (RPP) was in the design and construction phase. ${ }^{17,18}$ As the newest large-scale aqueous reprocessing facility under IAEA safeguards, the RPP instrumentation choices are informative. It is worth noting that many of the actual instrument systems (this is especially so for the IAEA systems) are custom built for a particular application (product containers, waste drums, hulls containers, etc.). These systems are not new technologies, per se, but do represent dedicated instruments optimized for anticipated plant specific material configurations. ${ }^{19,20}$

The standard classes of measurements and the typical instruments used for nuclear material accountability at reprocessing facilities are as follows:

1. Tank level indication. The standard instrument is a bubbler probe. Pressure differential readings from a reference probe and a movable probe allow the tank liquid level to be measured. This mature technology has been in use for many years.

2. Plutonium and uranium concentration. The standard is either hybrid k-edge densitometry (HKED), or mass spectroscopy, depending upon the information needed (typically $\mathrm{U}$ versus $\mathrm{Pu}$ ).

a. Measurement by HKED is a combination of x-ray fluorescence (XRF) and k-edge densitometry (KED). The XRF portion measures characteristic x-rays indicative of the element of interest. ${ }^{21,22}$ The KED measures the concentration of $\mathrm{Pu}$ by monitoring the transmission of gamma rays around the k-shell absorption edge. ${ }^{23}$

b. The standard methods for measuring mass spectroscopy are Isotope Dilution Mass Spectrometry, Thermal Isotope Mass Spectrometry, or Inductively Coupled Plasma Mass Spectrometry (ICPMS). While the sample preparation time and exact mechanism differs, all three operate by ionizing a portion of a sample, accelerating the ions, and measuring the mass of the ions as they pass through the system. The comparatively easier sample preparation of the ICP-MS system is making it the system of choice for many laboratories.

3. Isotopic determination. For relatively purified streams (product or waste streams with low overall levels of nuclear material) gamma-ray spectroscopy with a germanium detector (often referred to as HPG for high-purity germanium) is the standard measurement. ${ }^{24}$ Since gamma emission rates and energies are unique to each isotope, the isotopic (and therefore elemental) distributions can be measured with low uncertainty in most cases. ${ }^{25,26,27,28}$

4. Total nuclear material mass. Total mass of nuclear material can be obtained through coupling isotopic information from HPG measurements with neutron coincidence counting or calorimetry. The primary advantage these offer is that both NDA techniques can be performed on large (namely, a storage container with kilogram quantities of nuclear material product) items.

Calorimetry measures the total heat output of the item. The total mass of each isotope can be calculated by taking the decay rate and decay energy information for each isotope and using the isotopic ratios obtained via HPG measurements. 
Coincidence neutron measurements depend on the fact that fission events release more than one neutron in a very short (nearly instantaneous) time frame. Detecting the coincident neutrons will provide the total amount of "equivalent" material being measured. ${ }^{29,30}$ Again, as with calorimetry, combining this total with the isotopic ratios allows calculation of the mass of each isotope. Plutonium is especially suited to coincidence measurements, as the spontaneous fission of ${ }^{240} \mathrm{Pu}$ provides a built in neutron source. Higher actinides (especially $\mathrm{Cm}$ ) also provide spontaneous fission neutrons, whose presence complicates the measurement for impure products. ${ }^{31}$ Uranium products can also be measured in this manner, but an activation neutron source is required. Finally, methods such as "add-a-source" use an activation source for small quantities of $\mathrm{Pu}$ or other nuclear material. ${ }^{32}$

All of these technologies are well established and mature, even though they are still being improved and refined.

\subsection{Near-Real Time Accountancy}

One of the accountability issues that reprocessing plants must address is the accumulation of propagated errors in measured values. While many of the measurements described above have small inherent uncertainties (and improvements or new technologies will decrease them even further), when even these small uncertainties are propagated over the annual throughput (about 800 metric tons of SNF for RPP and 3,000 metric tons for the proposed U.S. facility) the uncertainty is too large to maintain acceptable accountability confidence. Accordingly, a process of near real-time accountancy (NRTA) is established. This process of NRTA allows "instantaneous" measurement of the nuclear material inventory in the plant at any given time by taking measurements and combining their analysis to provide a complete "picture in time" of the plant nuclear material inventory. Thus, not just the type of measurement is important, but the timing of the data collection and the application of the data to accountancy. The established NRTA systems, both by the operator and the IAEA accomplish this goal. ${ }^{33,34,35,36,37,38}$

\section{CONCLUSION}

Existing reprocessing facilities maintain accountability of their nuclear material. This is verified by the IAEA (or the appropriate agency for European facilities). They are able to measure their nuclear material inventories and operate NRTA systems to account for their nuclear material and keep the cumulative uncertainty under control. As new facilities are built, their increased size will complicate this issue, but it is not insurmountable. Current technology provides nuclear material concentration and total mass measurements, but the cumulative uncertainty propagated over the annual throughput is problematic. New technologies (improved measurements) and new analysis (improved NRTA) will therefore be necessary to maintain acceptable accountability in the proposed reprocessing facilities.

\section{REFERENCES}

1. W. Higinbotham, Editorial, Nucl. Mat. Man., Volume XIV, No. 2, (1984), pp. 3, 21.

2. F. Davis, "Safeguards and Security Concerns for New Processing Facilities," J. Nucl. Mat. Man., Vol. XVIII, No. 2, February 1990, pp. 28-29.

3. L. Bruckner, "A Measurement Control Program to Meet Desired Levels of Precision and Accuracy," J. Nucl. Mat. Man., Vol. XIX, No. 1, January 1991, pp. 29-32.

4. T. Shea, S. Deron, F. Franssen, D. Hope, N. Islam, S. Johnson, E. Kuhn, G. Laszio, D. Neal, and T. Renis, "Safeguarding Reprocessing Plants: Principles, Past Experience, Current Practice and Future Trends,” J. Nucl. Mat. Man., Vol. XXI, No. IV, July 1993, pp. 17-29. 
5. A. Adamson and V. Bychkov, "Current Trends in the Implementation of IAEA Safeguards," J. Nucl. Mat. Man., Vol. XXI, No. IV, July 1993, pp. 29-32.

6. K. Thomas and V. Longmire, IAEA Safeguards Approach for Reprocessing Facilities, Los Alamos National Laboratory, LA-UR-02-5276, 2002.

7. L. Lowry, R. Augustson, T. Canada, D. Cobb, and J. Shipley, Tokai Advanced Safeguards Technology Exercise Task T-F, Los Alamos Scientific Laboratory, LA-8070-MS, 1979.

8. IAEA, "Joint Use of Safeguards Equipment between the IAEA and an External Party," Policy Paper 20, International Atomic Energy Agency Department of Safeguards, SG-OP-GNRL-PL-0020, v. 1, 2006.

9. H. Menlove, M. Abhold, G. Eccleston, J. Puckett, T. Ohtani, H. Ohshima, H. Kobayashi, and S. Takahashi, "Smart Unattended Systems for Plutonium Safeguards," J. Nucl. Mat. Man., Vol. XXIV, No. IV, July 1996, pp. 17-24.

10. P. Durst, I. Therios, R. Bean, A. Dougan, B. Boyer, R. Wallace, M. Ehinger, D. Kovacic, and K. Tolk, Advanced Safeguards Approaches for New Reprocessing Facilities, Pacific Northwest National Laboratory, Rev 10, June 2007.

11. T. Burr, Material Balance Areas and Frequences[sic] for Large Reprocessing Plants, Los Alamos National Laboratory, LA-UR-94-2447 (1994).

12. M. Ehinger, N. Zack, E. Hakkila, and F. Fransen, Use of Process Monitoring for Verifying Facility Design for Large Scale Reprocessing Plants, Los Alamos National Laboratory, LA-12149-MS.

13. T. Burr, L. Wangen, and M. Mullen, Authentication of Reprocessing Plant Safeguards Data through Correlation Analysis, Los Alamos National Laboratory, LA-12923-MS, 1995.

14. E. Hakkila, N. Zack, M. Ehinger, and F. Franssen, "Use of Process Monitoring for Verifying Facility Design of Large-scale Reprocessing Plants," $13^{\text {th }}$ ESARDA Symposium on Safeguards and Nuclear Material Management, Avignon, France, LA-UR-91-1491, May 14-16, 1991.

15. W. Charlton, B. Fearey, C. Nakhleh, T. Parish, R. Perry, J. Poths, J. Quagliano, W. Stanbro, and W. Wilson, "Operator Declaration Verification Technique for Spent Fuel at Reprocessing Facilities," Nucl. Inst. and Meth. In Phys. Res. B, Vol. 168, 2000, pp. 98-108.

16. B. Cipiti, Advanced Instrumentation for Reprocessing, Sandia National Laboratories, SAND2005-6233, 2005.

17. R. Gutmacher, Measurement Uncertainty Estimates for Reprocessing Facilities, Los Alamos National Laboratory, LA-11839-MS, 1990.

18. S. Hsue and T, Sampson, "Nondestructive Assay Techniques and Associated Measurement Uncertainties," J. Nucl. Mat. Man., Vol. XX, No. 2, February 1992, pp. 17-25.

19. H. Menlove, E. Adams, E. Dahn, and A. Ramalho, Plutonium Canister Counter Operations and Procedures Manual, Los Alamos National Laboratory, LA-10615-M, 1986.

20. M, Swinhoe, C. Pearsall, T. Pochet, K. Fesrt, Rokkasho Hulls Monitor System Calibration Exercise June 2004, Los Alamos National Laboratory, LA-UR-04-5604, 2004.

21. T. Canada and S. Hsue, "A Note on the Assay of Special Nuclear Materials in Solution by X-ray Fluorescence,” J. Nucl. Mat. Man., Vol. XI, No. 2, Summer (1982), pp. 91-92.

22. D. Jedlovec, "Energy Dispersive X-ray Fluorescence Analysis of Uranium and Plutonium in Wet Scrap Process Solutions," Nucl. Mat. Man., Vol. X, No. 4, Winter 1981, pp. 37-41. 
23. J. Sprinkle and W. Hansen, K-Edge Densitometer (KED), Los Alamos National Laboratory, LA-UR-93-650, 1993.

24. W. Rodenburg and J. Fleissner, "Qualifying Nondestructive Assay for Plutonium Accountancy Measurements," Nucl. Mat. Man., Vol. XI, No. 2, Summer 1982, pp. 64-68.

25. T. Li, Y. Kuno, S. Sato, J. Parker, A. Kurosawa, T. Akivama, Development of Isotope Dilution Gamma-ray Spectrometry for Plutonium Analysis, Los Alamos National Laboratory, LA-UR-91-1567, 1991.

26. J. Akatsu, "Determination of Pu Amount in a Waste Carton by Gamma-ray Measurement," J. Nucl. Mat. Man., Vol. X, No. 4 Winter 1981, pp. 22-29.

27. J. Akatsu, T. Kimura, and H. Mutoh, "Gamma Ray Assay of a Waste Drum for the Determination of Plutonium Amount (III)," J. Nucl. Mat. Man., Vol. XVIII, No. 2, February 1990, pp. 21-25.

28. P. Russo and S. Hsue, The Effects of Fission Products on Demonstrated X-ray and Gamma-ray NDA Techniques Applies to Nuclear Materials Accounting in Reprocessing, Los Alamos National Laboratory, LA-9254-MS, 1982.

29. N. Ensslin, "Neutron Coincidence Counters for Plutonium Measurements," J. Nucl. Mat. Man., Vol. VII, No. 2, Summer 1978, pp. 43-65.

30. S. Croft, L. Bourve, D. Weaver, and H. Ottmar, ${ }^{، 240} \mathrm{Pu}$ Effective Mass of ${ }^{238} \mathrm{Pu}$ and ${ }^{242} \mathrm{Pu}$ in Relation to Passive Neutron Coincidence and Multiplicity Counting," J. Nucl. Mat. Man., Vol. XXX, No. 1, Fall 2001, pp. 10-19.

31. N. Miura and H. Menlove, The Use of Curium Neutrons to Verify Plutonium in Spent Fuel and Reprocessing Wastes, Los Alamos National Laboratory, LA-12774-MS, 1994.

32. H. Menlove, Passive Neutron Waste-drum Assay with Improved Accuracy and Sensitivity for Plutonium Using the Add-a-source Method, J. Nucl. Mat. Man., Vol. XX, No. 4, July (1992), pp. 17-26.

33. B. Jones, "Near Real Time Materials Accountancy at BNFL: Past, Present and Future," J. Nucl. Mat. Man., Vol XVII, No. 1, October 1988, pp. 17-19.

34. A. Islam, S. Johnson, and W. Sellinschegg, "Meeting Timeliness Requirements in Reprocessing Plants," J. Nucl. Mat. Man., Vol XXII, No. 1, October 1993, pp. 19-24.

35. W. Golly, R. Seifert, J. Lausch, and D. Schmidt, "Experience in Establishing Detailed Measurement Models for Real NRTA Balance Data," J. Nucl. Mat. Man., Vol. XX, No. 3, May 1992, pp. 34-42.

36. E. Hakkila, J. Barnes, R. Gutmacher, and R. Picard, Near-real-time Verification Approaches for the Process Area of Reprocessing Plants, Los Alamos National Laboratory, LA-11615-MS, 1989.

37. C. Coulter, T. Burr, E. Hakkila, H. Ai, I. Kadokura, and K. Fujimaki, Estimating Reprocessing Plant In-process Inventories by Simulation, Los Alamos National Laboratory, LA-UR-95-2155, 1995.

38. T. Burr, L. Wangen, and M. Mullen, Authentication of Reprocessing Plant Safeguards Data through Correlation Analysis, Los Alamos National Laboratory, LA-12923-MS, 1995. 